\title{
Burocracia e autoritarismo no Brasil: o caso do regime militar
}

\author{
Bureaucracy and authoritarianism in Brazil: \\ the case of the military regimen
}

\author{
Maurício Ferreira da Silva* \\ Professor, Colegiado de Ciências Sociais, Universidade \\ Federal do Recôncavo da Bahia - UFRB, \\ Cachoeira, Bahia, Brasil \\ e-mail: maufsilva@uol.com.br \\ *autor correspondente
}

Recebido: 16/02/2012

Aceito: 20/05/2012
RESUMO O artigo se propõe a uma análise da ditadura militar brasileira sob a perspectiva de Estado Burocrático-Autoritário apresentada por Guillermo O’Donnell. Para tanto, além das referências teóricas, se estrutura baseado em três linhas de abordagem que fundamentam a relação: a do processo político, que trata do movimento dos atores; a da legislação, que se refere ao conjunto de normas instituídas durante o regime e a econômica, que procura apontar o viés capitalista característico da ditadura militar.

PALAVRAS-ChaVe Ditadura militar; Burocracia; Autoritarismo; Segurança nacional; Dependência.

ABSTRACT The article proposes analysis of Brazil's military dictatorship from the perspective of bureaucratic-authoritarian state by Guillermo O'Donnell. To this end, besides the theoretical references, is structured based on three lines of approach that underlie the relationship: the political process, which deals with the movement of the actors; the law, which refers to the set of rules imposed during the regime and economic, which tries to point out the capitalism bias characteristic of the military dictatorship.

KEYWORDS Military dictatorship; Bureaucracy; Authoritarianism; National security; Dependence.

\section{Introdução}

As décadas de 1960 e 1970 foram cenário do surgimento de diversos golpes de Estado na América latina. Tais golpes proporcionaram a criação e manutenção de formas centralizadas de governo que, para uma forte vertente teórica, foram classificadas como modelos de Estado BurocráticoAutoritário. A concepção de Estado BA é explicada por Guillermo O’Donnell a partir de cinco características básicas. Em linhas gerais, e considerando a metodologia que aqui se desenvolveu, é possível enquadrá-las em três segmentos: o 
da ação dos atores, o segmento da exclusão política e do processo de despolitização e o segmento da exclusão econômica e aprofundamento do capitalismo periférico e dependente.

No primeiro segmento, O’Donnell trata dos atores envolvidos com a função de "gerenciamento". Afirma que os países que adotaram tal modelo possuíram, no alto comando do governo, pessoas com sólida carreira em organizações complexas e burocratizadas, como são os casos das Forças Armadas, de grandes empresas privadas e de áreas administrativas do próprio Estado. (O’Donnell, 1986: 21). Estes atores possuíam, em comum, um histórico de trabalhos burocráticos. O segundo segmento trata das questões mais diretamente ligadas ao aspecto político. No que concerne à participação, $\mathrm{O}^{\prime}$ Donnell afirma que os Estados BA compõem sistemas de exclusão política, pois fecham os canais de acesso da sociedade e impõem, através da repressão, controle vertical sobre instituições representativas, principalmente sobre os sindicatos. Já no que diz respeito à ação despolitizante, o estudo indica o propósito do BA de direcionar, para um "ambiente técnico", aquilo que se configura, na realidade, como ação política-administrativa, como as questões sociais e as políticas públicas. (O’Donnell, 1986: 21).

Por fim, ao terceiro segmento direcionam-se os fatores de ordem econômica. No sentido da exclusão, sinaliza que a ação prática do BA coloca em xeque as aspirações de participação das camadas populares nas questões econômicas, o que aprofunda as desigualdades inerentes do capitalismo. Este fato gera forte contradição ao ser comparado com o desenvolvimento industrial que, por sua vez, corresponde ao último aspecto deste segmento. Ao passo que a realidade socioeconômica determina desigualdades provenientes da exclusão econômica, a fase BA, segundo O’Donnell, compõe importante etapa de transformação dos mecanismos de acumulação existente nas sociedades de classe. Tais transformações, por consequência, contribuem para aprofundar "[...] um capitalismo periférico e dependente, mas dotado de uma extensa industrialização." (O’Donnell, 1986: 21).

Este artigo tem como objetivo mostrar a pertinência do enquadramento do regime militar brasileiro nos postulados sobre o modelo de Estado BurocráticoAutoritário apresentado por O’Donnell. Para tanto, a metodologia adotada segue a separação em segmentos apresentada anteriormente, logo, o texto será dividido em três seções temáticas: dos atores, da política e da economia.

\section{Atores e Processo Político}

Existe uma confluência de fatores que explicam porque o Brasil compôs um dos campos de atuação de setores conservadores com vistas à implantação do Estado Burocrático-Autoritário. Em linhas gerais, contudo, pode-se aferir que o golpe de Estado de 1964 não deve ser visto de forma isolada, mas como parte da estratégia de controle ideológico no continente. A queda de João Goulart representou o início do ciclo militar no país, mais precisamente, do denominado regime militar.

A participação dos atores no processo que desencadeou o golpe de Estado foi determinante na escolha do novo presidente. O Marechal Humberto Castello Branco, então chefe do Estado-Maior das Forças Armadas, teve seu nome referendado não apenas pelo alto escalão militar, mas também pelos civis que participaram, direta ou indiretamente, do golpe. Segundo pronunciamentos do próprio presidente, seu governo deveria ter como objetivo "limpar" as instituições políticas, retirando os “obstáculos impatrióticos". (Tavares, 1977: 102). Vigorou sob a dicotomia entre os que defendiam o pronto restabelecimento da democracia e os que almejavam o aprofundamento do autoritarismo, o que gerou dois campos distintos dentro das Forças Armadas, como atesta o General Ernesto Geisel:

Foi um erro ter-se ficado tanto tempo. Surgiu, desde logo, o problema do combate ao comunismo, ao terrorismo, à corrupção. Além disso, manifestou-se outro problema grave: o da divisão no Exército entre a linha dura e a área mais moderada, que tendia para a normalização. [...] Havia muitos oficiais que eram moderados e cuja tendência era se agrupar em torno de Castello. E havia outros que eram mais exaltados, mais radicais, e que se uniram em torno do Costa e Silva. (D'Araujo e Castro, 1998: 168).

Entretanto, o que se viu, a seguir, foi a implantação de um regime de exceção estimulado pela decretação de atos institucionais, principalmente para a escolha do presidente da república. Ora, a restrição à participação política corrobora um dos preceitos levantados por Guillermo O'Donnell acerca do Estado Burocrático-Autoritário: a supressão da cidadania no sentido da participação política. Segundo tal formulação, o modelo de estado BurocráticoAutoritário (BA) se caracteriza como a ruptura de sistemas de representação democrática.

Essa ruptura é motivada, segundo O'Donnell, pelo fato de que, para os responsáveis pelo BA, o que 
coloca em risco a manutenção do Estado ${ }^{1}$ Capitalista é a proliferação de movimentos contestatórios nos diversos níveis da representação política. Logo, sua principal característica é a da defesa da organização capitalista em seus principais aspectos, ou seja, a economia de mercado e o modelo de estado. Assim, o BA mira o conjunto de características vinculadas à cidadania e nelas descarrega o arsenal de medidas que, do ponto de vista ideológico, expõe as entranhas do autoritarismo. Nesse sentido a cidadania é combatida em termos da organização institucional e dos canais de participação da vida política, ou seja, na proibição da organização da sociedade em instituições representativas (sindicatos, movimentos sociais, etc.) e nas que dizem respeito ao acesso a canais de participação direta (principalmente os partidos).

Seria leviano afirmar que, na hipótese da ausência de um setor mais "duro" entre os militares, a democracia seria restabelecida. Se levarmos em consideração os diversos agenciamentos do cenário, pode-se constatar que a tendência, naquele momento, era de "fechamento" e não de "abertura", principalmente em se considerando a conjuntura internacional e o acirramento da Guerra Fria. Além disso, os membros do governo provenientes da Escola Superior de Guerra ocupavam cargos importantes na administração superior e possuíam um claro projeto nacional, principalmente no âmbito econômico.

De qualquer forma, é fato que a configuração de dois grupos distintos proporcionou situação favorável à escolha de Costa e Silva para a sucessão de Castello Branco. Na verdade, seu nome representou uma imposição do comando militar, tanto na análise de Ernesto Geisel quanto do General Hugo de Abreu. Para Abreu, a atitude de cerceamento do processo eleitoral tomada por Castello Branco, além de causar o primeiro desvirtuamento dos princípios que levaram à "Revolução", visou evitar um mal maior (Abreu, 1980: 64). Por sua vez, Geisel ressalta o desejo de Castello Branco em devolver o comando do Executivo para um civil:

Veio a sucessão, e Castello pensou num candidato civil. Era o sonho dele. Mas era um sonho utópico naquelas circunstâncias [...] Pensou em fazer do Bilac Pinto o novo presidente da República. Depois pediu uma lista aos políticos do partido do governo, com cinco nomes. Mas isso não deu em nada. Os políticos e a maioria dos militares se

\footnotetext{
${ }^{1}$ O`Donnell enquadra o Estado no âmbito das relações de dominação que preenchem a estrutura social, ou seja, é caracterizado como relação social de dominação. Assim - e tendo em vista a condição inerente do conjunto das relações de dominação - tem a capacidade de operar a partir de instituições específicas de coação com o propósito de organizar as relações sociais. Logo, reside no âmbito da sociedade civil, mesmo que suas resoluções operem na coação desta sociedade civil. (O’Donnell, 1986: 16)
}

fixaram no nome do Costa e Silva. Passou a ser um fato consumado. (D'Araujo e Castro, 1998: 168).

No dia 15 de Março de 1967, o Marechal Costa e Silva tomava posse. Seu governo foi marcado pelo aprofundamento do autoritarismo em uma conjuntura de maior questionamento da legitimidade do regime. A abertura política tornou-se pauta na agenda de diversos segmentos da sociedade civil, principalmente de setores que haviam apoiado o golpe de 1964. Carlos Lacerda transformou-se em ferrenho crítico e encabeçou a Frente $\mathrm{Ampla}^{2}$, juntamente com Goulart e Kubitschek. Paralelo a isso, mesmo tendo se credenciado como representante da chamada "linha dura" do regime, as ações de controle do presidente passaram a ser questionadas pela elite militar, acirrando ainda mais os debates internos:

Costa e Silva veio como representante da 'linha dura', embora cedo a tenha desapontado com seu espírito liberal. Mas o ciclo vicioso já estava implantado: a violência e sua repressão acabaram criando o clima que obrigou Costa e Silva a aceitar o A.I. 5. (Abreu, 1980: 257).

O ano de 1968 pode ser considerado "marco" na estruturação e formalização do modelo burocráticoautoritário brasileiro. Sob os auspícios da crescente onda de contestação do regime, o comando governista se "viu forçado", segundo argumento de Lyra Tavares, a "radicalizar" no sentido das regras de controle (Tavares, 1977: 135). Costa e Silva não demonstrava satisfação com as soluções de cunho autoritário encontradas para resolver os conflitos. Talvez por influência de seu perfil liberal, manifestado por Abreu e Geisel, ele tenha procurado uma alternativa para a crise dentro dos parâmetros constitucionais. E esta alternativa foi, de acordo com Geisel, a preparação de uma nova Carta Constitucional, elaborada com o auxílio do vice-presidente Pedro Aleixo, mas que não chegou a ser promulgada em função do acidente vascular que o acometeu. (D'Araujo e Castro, 1998: 210).

Foi este acidente vascular o responsável por seu afastamento. A priori, o que as diretrizes legais previam era a substituição automática por Pedro Aleixo. No entanto, tendo em vista a pouca confiança da elite militar em um civil, nova "alternativa" foi elaborada. Um golpe na avaliação de Ernesto Geisel.

\footnotetext{
2 Consistiu em movimento que, em linhas gerais, reivindicava a redemocratização do país. Agregou diversas correntes durante o tempo em que se manteve ativo. Além de Lacerda, Goulart e Kubitschek, partidários dos diversos partidos de oposição e segmentos organizados da sociedade ali atuaram. (Silva, 1983: 27)
} 
Fala-se em golpe de 64, mas o golpe realmente foi dado quando impediram Pedro Aleixo de tomar posse. Por que Pedro Aleixo não assumiu? Porque era um político, e fora o único membro do governo a votar contra o A.I. 5. Achavam que ele não ia dar conta do problema. A primeira coisa que haveria de querer era derrubar o A.I. 5. Por isso, concluíram que não podia assumir. (D'Araujo e Castro, 1998: 210).

Uma junta militar, formada pelos ministros Augusto Rademaker (Marinha de Guerra), Aurélio de Lyra Tavares (Exército), Márcio S. Mello (Aeronáutica) assume o comando do poder Executivo. E foi desta junta a responsabilidade pelas decretações da Emenda Constitucional de $n^{\circ} 1$ - que dava nova redação à Constituição de 1967 - e da Lei de Segurança Nacional. Tais regulamentações foram fundamentais para o aprofundamento do aspecto autoritário do regime.

\section{Exclusão e Despolitização pela ótica da Legislação}

Tanto a Carta Constitucional de 1969 quanto a Lei de Segurança Nacional foram fundamentais para à convergência dos preceitos apresentados por O’Donnell em torno da exclusão da sociedade da dinâmica política e do processo de despolitização das ações de governo. Por isto, esta seção subdivide-se justamente entre os dois documentos.

\section{Constituição de 1967 e 1ª Emenda de 1969}

A Constituição de 1967 é resultado da "pressão" sofrida pelo excesso de emendas e atos institucionais impostos a partir de 1964. Seu mecanismo de elaboração seguiu os critérios ditatoriais implantados a partir do golpe, já que o presidente Castello Branco, ao decretar o Ato Institucional número 4 em 12 de Dezembro de 1966, atribuiu poderes constituintes ao Congresso Nacional de então. (Vieira, 1988: 89). Em outras palavras não houve - como é de praxe - a convocação de uma Assembléia Nacional Constituinte, mas a transformação do Congresso Nacional em Assembléia Constituinte.

Considerando que o atual Congresso Nacional, que fez a legislação ordinária da Revolução, deve caber também a elaboração da lei constitucional do movimento de 31 de Março de $1964 .^{3}$

\footnotetext{
3 Ato Institucional Número 4, de 12 de Dezembro de 1966. In (Vieira, 1988: 89).
}

Esta manobra condiz com o princípio do Estado autoritário implantado a partir do golpe. Submeter os demais poderes aos ditames do Executivo, retirando deles a autonomia que rege o preceito liberal-republicano tornou-se uma prática constante. Prova disso é que esta Carta, segundo Vieira, é fruto de um texto criado pelo próprio Executivo com o auxílio técnico de alguns juristas e posteriormente remetido ao Congresso Constituinte para simples apreciação (Vieira, 1988: 89), o que pressupõe sua aprovação sem o devido debate e inserção dos representantes da sociedade. $\mathrm{O}$ texto versa sobre a consolidação de um sistema democrático representativo, corroborando o discurso adotado após o golpe. No entanto a realidade dos fatos comprova justamente o contrário.

Em nenhum momento sequer se cogitou da convocação de uma Assembléia Constituinte, e o texto apresentado pela presidência da república para votação apenas buscava organizar o país de acordo com as várias modificações que os atos institucionais e emendas já haviam realizado. (Quirino e Montes, 1987: 66).

Em linhas gerais, o texto apenas incorpora para o âmbito da Constituição os atos e decretos impostos no período pré-67. A nova Constituição aprofunda ainda mais a limitação à participação política em todos os níveis. Ao comparar algumas disposições que tentam manter as bases de uma estrutura democráticorepresentativa com outras inseridas no conjunto dos direitos concedidos aos indivíduos, evidenciam-se diversas contradições. Estas contradições, longe de representar uma ambigüidade involuntária, têm a nítida função de camuflar a centralização autoritária no controle da ação política, denotando a divergência com os preceitos que sustentam a democracia liberal propagada no texto. Já no capítulo IV, temos um nítido exemplo desta dicotomia:

Por motivo de crença religiosa ou de convicção filosófica ou política, ninguém será privado de qualquer dos seus direitos, Salvo se o invocar para eximir-se de obrigação legal a todos imposta, caso em que a lei poderá determinar a perda dos direitos incompatíveis com a escusa de consciência. ${ }^{4}$

De início, pode-se o sexto parágrafo em duas partes que, analisadas sob o mérito da ação política, se interligam nos objetivos estratégicos do regime. Condizente aos preceitos democráticos tradicionais, o sistema ratifica a liberdade individual no âmbito da realidade política, garantindo-a como direito

\footnotetext{
${ }^{4}$ Capítulo IV, Artigo 153, Parág. 6º. In (Constituição da República Federativa do Brasil. 19ª Edição. São Paulo: Atlas, 1983).
} 
universal. No entanto, ressalta que este direito limita-se ao cumprimento das obrigações impostas pela lei, ou seja, estabelece uma limitação da ação política, e invoca o direito "legal" de determinar punição quando tal ação entrar em desacordo com aquilo que se espera do resultado da consciência.

Eis aí manifestada a primeira dicotomia: a ação de consciência. Ora, ao determinar limites para a ação de consciência, esta lei nada mais faz do que impor aquilo que deve ser a ação no âmbito político. Consciência e ação limitam-se à cartilha de regras impostas a todos pela "democracia" militar. Mais adiante, no oitavo parágrafo, a dicotomia se acentua e a "cartilha" torna-se mais nítida:

É livre a manifestação de pensamento, de convicção política ou filosófica, bem como a prestação de informações independentemente de censura, salvo quanto a diversões e espetáculos públicos, respondendo cada um, nos termos da lei, pelos abusos que cometer. É assegurado o direito de resposta. A publicação de livros, jornais e periódicos não depende de licença da autoridade. Não serão, porém, toleradas a propaganda de guerra, de subversão da ordem ou de preconceitos de religião, de raça ou de classe, e as publicações e exteriorizações contrárias à moral e aos bons costumes. ${ }^{5}$

Propaganda de guerra; subversão da ordem. É através destas demonstrações que a "cartilha" da conduta política do regime militar se apresenta na Constituição de 1967. Este parágrafo, por ser o mais longo dentre os que foram redigidos no quarto capítulo, traz à luz importantes considerações.

Em primeiro lugar, vinculado ao que foi anteriormente analisado, vale ressaltar a referência à "ação de consciência". O texto se utiliza de definições subjetivas que visam fornecer opções para a ação repressivo-autoritária. E isto se manifesta através da ameaça de punição aos abusos que possam ser cometidos e da não tolerância à propaganda de guerra e de subversão da ordem. Ora, e o que são os abusos e a propaganda de guerra e de subversão senão uma suposta manifestação em contrário àquilo que se espera? E o que se espera senão uma ação política em conluio com a doutrina autoritária? Em suma, a liberdade manifestada para o pensamento, também aqui, confronta-se com as limitações da ação política, que, além de justificar o pressuposto apresentado em torno da "democracia" propagada no contexto geral da Carta, submete os indivíduos a enquadramento

\footnotetext{
${ }^{5}$ Capítulo IV, artigo 153, parág. $8^{\circ}$. In (Constituição da República Federativa do Brasil. 19ª Edição. São Paulo: Atlas, 1983).
}

subjetivo e legal. Esse mesmo enquadramento pode ser percebido de forma contundente no âmbito das punições:

O abuso de direito individual ou político, com propósito de subversão do regime democrático ou de corrupção, importará a suspensão daqueles direitos de dois a dez anos, a qual será declarada pelo Supremo Tribunal Federal, mediante representação do Procurador-Geral da República, sem prejuízo da ação cível ou penal que couber, assegurada ao paciente ampla defesa. ${ }^{6}[\ldots]$ Quando se tratar de titular de mandato eletivo, o processo não dependerá de licença da Câmara a que pertencer.?

O texto denota a capacidade imposta pelo regime de cassar os mandatos dos que subvertem a ordem, logo, se coaduna à estratégia da doutrina autoritário-militar no aspecto da participação políticainstitucional. Abre-se, assim, a possibilidade de penalizar opositores com método diferenciado, uma vez que o processo centraliza-se no judiciário. No caso dos parlamentares eleitos, exclui-se a prerrogativa da imunidade parlamentar, liberando o enquadrado independentemente do aval das Câmaras.

Neste último caso, além de ferir um dos preceitos básicos da democracia representativa liberal, a medida, atrelada aos fatores subjetivos da "cartilha", viabilizava o aumento da probabilidade de apoio também do poder legislativo ao processo de legitimação do regime. Por último, e no intuito de fundamentar também aqui a dicotomia manifestada durante esta seção, vale salientar a "insistente" definição conceitual dada pelos militares ao sistema que inauguraram.

Talvez pela genérica concepção que o termo democracia pode gerar, ou talvez como uma estratégia de ludibriar a opinião pública com eleições pontuais que venham a encobrir a estrutura nitidamente autoritária, esta definição se apresenta sorrateira no conjunto da Carta. Longe de descartar completamente a primeira, o fato é que a segunda hipótese se apresenta de forma mais nítida.

Em razão de sua ilegitimidade e, também, de seu conteúdo autoritário absorvendo os atos revolucionários de 1964, podemos classificar a Constituição de 1967 dentro da categoria jurídicopolítica de Estado de Exceção híbrido ou regime misto. (Vieira, 1988: 90).

\footnotetext{
${ }^{6}$ Artigo 154. In (Constituição da República Federativa do Brasil. 19 Edição. São Paulo: Atlas, 1983).

7 Artigo 154/ parág. Único. In (Constituição da República Federativa do Brasil. 19ª Edição. São Paulo: Atlas, 1983).
} 
Ora, apesar do discurso contraditório, o fato é que o processo político deflagrado a partir do golpe de 1964 cristalizou uma realidade autoritária e burocrática no âmbito da organização política nacional. A perspectiva legislativa demonstra o esforço na tentativa de divulgar classificações que coloquem em dúvida a verdadeira face autoritária e burocrática do regime. Tal iniciativa se manifesta ainda mais nitidamente no conteúdo da Lei de Segurança Nacional, principalmente por definir o pensamento contraditório como nocivo à nação. O código reflete o cenário político condizente com o período - como o caso da instauração da pena de morte - e seu estudo é de fundamental importância à compreensão da realidade sociopolítica.

\section{A Lei de Segurança Nacional}

A Lei de Segurança Nacional foi promulgada numa conjuntura de intensas manifestações sociais. $\mathrm{Na}$ realidade, as manifestações nunca deixaram de existir, em maior ou menor grau, desde 1964. A diferença agora é que passaram a ocorrer sob uma condição normativa mais rígida, particularmente a partir da decretação do AI-5. Mesmo contando com determinados decretos que previam o chamado crime político - como o julgamento do processo no âmbito da Justiça Militar, "faltava" ao regime um código específico que abarcasse a nova realidade contestatória, em outras palavras, ampliar e legitimar as ações repressivas no âmbito do controle social. A LSN representa esta amplitude e se coaduna com o conjunto de normas decretadas pela Junta Militar.

Seu caráter é extremamente genérico. Ela objetiva definir regras que possam reprimir ações contrárias à "ordem nacional" e direciona os tentáculos para diversas esferas da organização social. Seu conteúdo inspira-se em preceitos provenientes de setores das Forças Armadas, principalmente da Escola Superior de Guerra (ESG) que, pelas palavras do então Ministro da Justiça do governo Médici, possui relação de influência política.

A segurança nacional é, como lembra o General Eduardo D. Oliveira ${ }^{8}$, - de resto exprimindo a própria conceituação da Escola Superior de Guerra - "o grau relativo de garantia que, através de ações políticas, econômicas, psicossociais e militares, o Estado proporciona, em determinada época, à Nação que jurisdiciona, para a consecução ou manutenção dos objetivos nacionais, em face dos antagonismos existentes". (Buzaid, 1971: 121).

\footnotetext{
${ }^{8}$ Refere-se a "Eduardo Domingues de Oliveira, Segurança Nacional. Revista Brasileira de Estudos Políticos, vol. 21, p. 79" In (Buzaid, 1971: 122).
}

Por tratar-se de matéria complexa, uma vez que delineia a globalidade daquilo que se entende por Segurança Nacional, a referência aqui será a apenas dois grupos de implicações que, agrupados, corroboram a analogia ao modelo burocráticoautoritário apontado por Guillhermo O'Donnell. O primeiro diz respeito à classificação adotada pelos militares acerca dos conflitos pós-golpe, definida como guerra revolucionária. A segunda direciona-se às transgressões e penalidades apresentadas no texto, tendo como ênfase a representação política.

A noção de guerra revolucionária é utilizada na Lei para se referir ao pensamento contrário e aos opositores do regime. O terceiro parágrafo do primeiro capítulo a define como conflito interno de inspiração ideológica, que conta com o auxílio do exterior para a conquista progressiva do controle político do país. $\mathrm{O}$ texto se coaduna com a definição do Estado Maior das Forças Armadas:

Guerra revolucionária é a guerra interna, de concepção marxista-leninista de possível adoção por movimentos revolucionários diversos que, - apoiados em uma ideologia, estimulados e, até mesmo, auxiliados do exterior, - visam à conquista do poder, através do controle progressivo, físico e espiritual da população sobre que é desencadeada, desenvolvendo-se segundo processo determinado, com a ajuda de técnicos particulares e da parcela da população assim subvertida. ${ }^{9}$

Portanto, o que se compreende por guerra revolucionária, segundo o ponto de vista das próprias Forças Armadas, são ações de grupos politicamente desvinculados da ideologia específica que norteia todo o funcionamento do regime militar. Vinculados a pressuposto de orientação capitalista, as ações do governo militar nos campos social, político e econômico visam à manutenção e estabilidade desta ordem. Ademais, a fim de demonstrar suposto caráter nacional em torno destes princípios, a Lei de Segurança Nacional reitera as influências de forças externas aos opositores.

Logo, pode-se aferir que a Lei de Segurança Nacional constituiu-se em instrumento de legitimação da ordem autoritária militar de orientação capitalista, visto que criou um arcabouço "legal" de repressão aos grupos vinculados a ideologias divergentes. Além disso, estabelecidas em contexto marcado pela Guerra-Fria, tais regras serviram para delimitar o campo escolhido pelo regime.

\footnotetext{
${ }^{9}$ PINTO, Bilac. "Guerra Revolucionária" Estado-Maior das Forças Armadas, FA, E,OI/61. Revista Forense, 1964. In (Cogan, 1976: 06).
} 
Exemplo mais contundente neste sentido é a abordagem em torno da relação entre partido político e segurança nacional, presente no segundo capítulo. Seu conteúdo classifica as organizações partidárias de orientação ideológica divergente como subversivas, e a tentativa de alavancá-las como atentado à segurança.

Reorganizar ou tentar reorganizar, de fato ou de direito, ainda que sob falso nome ou forma simulada, partido político ou associação, dissolvidos por força de disposição legal ou de decisão judicial, ou que exerça atividades prejudiciais ou perigosas à segurança nacional, ou fazê-lo funcionar, nas mesmas condições, quando legalmente suspenso [...] Pena: Reclusão, de 2 a 5 anos. $^{10}$

O mesmo artigo estende a contravenção para o âmbito das "associações" que, de forma genérica, englobam outras formas de representação não partidárias, como as estudantis e as de trabalhadores. Ora, ao limitar a linha de ação no âmbito da representação, a LSN "regulamenta" o dispositivo constitucional da Carta de 1967, que prevê a pluralidade partidária; ao fazê-lo, credencia-se como suporte à contradição já apontada anteriormente, uma vez que o texto especifica a perseguição a partidos "clandestinos", sem citar o bipartidarismo exposto no AI ${ }^{11}$. Trata-se, pois, de tornar "legítimo" o que, pelo próprio preceito constitucional, se configura como "ilegítimo". O autoritarismo se consolida, assim, pela supremacia do Ato Institucional sobre a Carta Constitucional.

Em que pese às discrepâncias subjacentes à relação autoritarismo-democracia, é necessário ressaltar que o regime militar optou pela tentativa de manter vivas algumas iniciativas no âmbito político-institucional capazes de fomentar uma perspectiva "legítima". Isso porque, como citado anteriormente, ele emerge justamente com o discurso de garantia da conservação da ordem legal vigente antes do golpe. Dessa forma, alguns dispositivos próprios da democracia representativa - como as eleições legislativas e a existência de partidos - convivem com a centralização das decisões políticas no âmbito do Executivo.

No Brasil o Castelismo acreditou ser possível salvar parte das instituições da democracia política; e claro, a dinâmica autoritária da situação levou a caminhos muito diferentes dos

\footnotetext{
${ }^{10}$ Artigo 43. In (Cogan, 1976: 57).

${ }^{11}$ Segundo Maria D'alva Kinzo, a adoção do mecanismo bipartidário responde a dois anseios do regime, que são os de estabelecer uma base de apoio segura, com a extinção de partidos já tradicionais no ontexto eleitoral brasileiro, e fugir da conotação negativa inerente ao modelo de partido único. (Kinzo, 1988: 28).
}

previstos por dito grupo, mas ficaram resíduos - o parlamento, os dois partidos oficiais, o chamado de vez em quando a eleições para posições não executivas - que mostraram nos últimos anos o outro lado da questão: a dinâmica própria que contém a postulação da democracia, por mais surrealista que apareça quando é planteada e durante o BA. (O'Donnell, 1986: 40).

E é esta a realidade que se apresenta no governo de Emílio Garrastazu Médici, ou seja, um sistema representativo proveniente de uma realidade bipartidária definida segundo critérios autoritários. Sua relação com o poder legislativo leva em conta todos estes aspectos, visto que as eleições de 1970 lhe garantiram uma folgada maioria no Congresso Nacional e a Lei de Segurança Nacional uma relativa tranqüilidade frente a possíveis questionamentos da oposição organizada no MDB (Movimento Democrático Brasileiro).

Decorre daí a instabilidade de ação do poder Legislativo frente ao poder Executivo comandado por Médici. Segundo Lúcia Klein e Marcus Figueiredo, após a reabertura de 1969, o Congresso procura definir uma linha de ação próxima daquilo que se configurava antes do golpe, ou seja, fazer com que as casas reavivassem a ação em torno do debate político. Esta postura era reivindicada tanto pela oposição quanto pelo próprio partido governista. No entanto o que se viu foi, na verdade, a "condenação" das casas a uma postura eminentemente técnica, sem que pudessem participar das decisões determinantes no âmbito político-administrativo do país. Isto se deve, principalmente, de acordo com Klein e Figueiredo, à própria natureza do processo, uma vez que o AI-5 se impõe como mecanismo revolucionário de intervenção e paira como uma constante ameaça tanto para a ação coletiva - no caso do funcionamento normal das casas - quanto para as individuais - pelo fato de não existir imunidade para os "crimes" contra a revolução.

Desde então o Congresso se viu diante do impasse de atuar segundo normas que, além de não especificarem com clareza as suas funções, podem ter sua vigência suspensa de um momento para o outro, sem aviso prévio, na medida em que nunca se sabe quando o Executivo vai agir de acordo com suas prerrogativas constitucionais ou revolucionárias, ou seja, com base em procedimentos legais ou carismáticos. (Klein e Figueiredo, 1978: 34).

Ora, é este sentido de exceção que constitui a essência das afirmações de O'Donnell. O modelo Burocrático-Autoritário, dentro de seus aspectos eminentemente políticos, converge neste sentido. Trata-se do cerceamento da participação do indivíduo, 
seja em relação aos canais de participação tradicionais, como os partidos e o parlamento, ou mesmo dos segmentos de classe, como os sindicatos e associações. Este princípio excludente se verificará, também, em torno dos fatores de ordem econômica.

\section{Exclusão Econômica e Desenvolvimento}

Como vimos, o estado capitalista, segundo O'Donnell, caracteriza-se como mecanismo de sustentação e manutenção das diversas desigualdades sociais manifestas na realidade social, principalmente naquilo que tange às relações de produção. Para tanto, atua a partir de suas instituições e do direito, ou seja, dos diversos órgãos criados para colocar em prática o controle social e o conjunto de leis criadas em consonância com a realidade da economia de mercado.

Uma vez desigual pela própria "natureza" que norteia o capitalismo, o estado se configurará, portanto, como suporte deste processo. E como mostrado anteriormente, é justamente em torno da manutenção da estrutura capitalista que emerge o estado Burocrático-Autoritário. Segundo O’Donnell, as condições surgidas com a perspectiva de ruptura deste modelo propiciaram a conjuntura necessária para a eclosão de sistemas políticos centralizados na América Latina (O’Donnell, 1986: 16). Todos os países que adotaram o B.A. tiveram, como predecessores, movimentos contestatórios da então vigente estrutura capitalista.

No caso do Brasil, o projeto econômico implementado a partir do golpe de 1964 procurou se contrapor ao ritmo de desenvolvimento que se verificava durante o governo de João Goulart. O projeto "pós-golpe" se prevaleceu da contribuição de órgãos criados pela elite econômica que tentaram estabelecer condição de mobilidade e de transformação às propostas reformistas incitadas por Goulart. Cabe referência especial neste sentido à atuação do IBAD (Instituto Brasileiro de Ação Democrática) e do IPES (Instituto de Pesquisas e Estudos Sociais). Portanto, vale aferir aqui que o conjunto de medidas impetradas no âmbito da política econômica também contou, e muito, com a participação de grupos específicos de ação. Logo, a estruturação e as conseqüências deste modelo não são de exclusiva autoria da elite militar.

A vanguarda da poderosa coalizão burguês antipopulista e antipopular, localizada nos vários escritórios de consultoria, anéis burocráticosempresariais, associações de classe dominantes e militares ideologicamente congruentes, beneficiando-se do apoio logístico das forças transnacionais, transformou-se num centro estratégico de ação política, o complexo IPES/ IBAD. Juntamente com fundadores e diplomados da ESG, ele estabeleceu a 'crítica das armas', representando o momento político-militar da ação burguesa de classe. (Dreifuss, 1981: 143).

$\mathrm{O}$ esforço em modificar as prioridades elencadas e iniciadas no governo de Goulart inaugurou nova fase da economia nacional, aumentando o foco internacional. $\mathrm{O}$ processo de maior impulso na internacionalização das questões econômicas foi, segundo Fernando Henrique Cardoso, resultado de nova divisão internacional do trabalho, onde parte do sistema industrial dos países mais desenvolvidos é transferida para os países em fase inferior de desenvolvimento, dentre estes o Brasil da década de 1960.

O ingresso da política centrista de cunho autoritário possibilitou, de acordo com Cardoso, um modelo de desenvolvimento dependente que permitiu dinamismo, ou seja, forneceu possibilidades variadas na atuação dos setores de produção. Além disso, permitiu maior crescimento econômico, visto que os investimentos internacionais tornaram-se mais volumosos e propiciou maior mobilidade social nas áreas da sociedade influenciadas pela produção industrial. (Cardoso, 1972: 65). No entanto, para Cardoso, este processo estimulou aumento dos níveis de desigualdade social.
Os ministros encarregados desta área tudo fizeram para combater as impurezas que perturbavam o modelo econômico com que sonhavam: cercearam os interesses agraristas na política do café, censuraram os 'empresários parasitas', criaram os instrumentos, apelara, enfim, para a primazia do Capital (e, primus inter pares, do capital estrangeiro). (Cardoso, 1975: 199).

Nesse contexto, a economia torna-se dependente do controle salarial - no intuito de limitar o consumo - e do controle sobre os gastos públicos. A este processo alia-se o fato de que o governo militar abdica de impetrar processo de modernização do setor empresarial, incentivando a concorrência e, por conseqüência, gerando um processo desenvolvimentista nacional. Em suma, ao abrir-se para nova conduta internacional no processo de produção em detrimento da modernização privada interna, o estado delineia as matrizes do processo intervencionista, acentuando a importância da burocracia a partir do incentivo à participação estatal.

Com isso, em vez do fortalecimento da 'sociedade civil' - das burguesias - como parecia desejar a política econômica-financeira, foi-se robustecendo a base para um Estado expansionista, disciplinador e repressor. Quebraram-se os sindicatos, quebraram-se os habituais limites e formas de inter-relação entre o interesse privado e o público, passou-se à 'legisferação' por decretos como rotina. (Cardoso, 1975: 199). 
A dinâmica estabelecida pelo estado militar atribui, segundo Cardoso, importância significativa para a burguesia internacional no âmbito da organização política formal. E isto ocorre em detrimento dos grupos nacionais que, em tese, deveriam reivindicar para si este papel. No entanto, como afirma Cardoso, esta "apatia" se explica por dois motivos básicos. Em primeiro lugar o fato de que, aliada aos militares e ao estado, a burguesia visa um inimigo comum, ou seja, a ameaça de uma política voltada ao favorecimento das classes populares. E, em segundo, a burguesia nacional jamais deixou de acreditar que pudesse "pegar carona" no veículo do desenvolvimento impetrado pelo estado, daí o fato de submeter-se à regulamentação imposta à área econômica.

Esta forma de intervencionismo, no entanto, sofreu variações decorrentes das próprias cisões internas da elite diretiva. Cardoso ressalta que a dinâmica adotada no início do governo Castello Branco pressupunha conduta mais "liberal" em termos políticos e, principalmente, econômicos, mantendo a regulamentação estatal, mas com o fortalecimento da empresa privada. Logo, não havia nem a modernização burocrática, nem o crescimento acentuado do setor público.

\section{Não foi um modelo deste tipo que as Forças Armadas implementaram: assumiram, como objetivo político, é certo, o reforçamento do Exército, previsto pelo projeto político governamental, mas puseram-no sob seu controle direto. [...] Passaram também a sustentar políticas com o objetivo de controlar certas áreas econômicas e de manter o crescimento econômico. (Cardoso, 1972: 66).}

As prerrogativas repressivas do modelo autoritárioburocrático sobressaíram-se sobre os preceitos liberais do início do golpe. Claramente motivada pela ala mais radical das Forças Armadas, a repressão, segundo Cardoso, conseguiu tornar-se eficiente para o sistema, traduzindo-se naquilo que ele definiu como "estabilidade social com dinamismo econômico", ou seja, uma economia em constante mutação sem possíveis reveses provenientes da dinâmica social. E isto foi possível dada à condição de que, através da política de Segurança Nacional, houvesse a repressão em torno dos grupos de ação política, principalmente as representações trabalhistas. A repressão contribuiu, assim, com a "[...] retomada do desenvolvimento, isto é, a acumulação capitalista em escala ampliada." (Cardoso, 1972: 67).

\section{Considerações Finais}

Costa e Silva assumiu o comando do governo autoritário-militar reagrupando segmentos que, durante o governo anterior, foram alijados da estrutura político-econômica, dentre estes estão o empresariado nacional e os grupos radicais e estatizantes da elite militar. Assim, o estado burocrático-autoritário ganhou nova dimensão com a redefinição do papel exercido pela burguesia nacional.

A relação entre uma forma de governo autoritária - sustentada sobremaneira em decretos - e o desenvolvimento econômico, transformou o Brasil, segundo aponta Guillermo O’Donnell, em um caso único entre os modelos B.A. analisados na América Latina. E isto ocorre porque, mesmo havendo forte expansão estatal, o regime

[...] se voltou a amparar algumas frações da burguesia local, sem que se rompesse a aliança original com a grande burguesia. (O'Donnell, 1986: 33).

\section{Referências}

Abreu, Hugo. 1980. Tempo de Crise. Rio de Janeiro: Ed. Nova Fronteira.

Buzaid, Alfredo. 1971. Conferências. Brasília: Departamento de Imprensa Nacional.

Cardoso, Fernando Henrique. 1975. Autoritarismo e Democratização. Rio de Janeiro: Paz e Terra.

Cardoso, Fernando Henrique. 1972. O Modelo Político Brasileiro e Outros Ensaios. São Paulo: Difusão Européia do Livro.

Cogan, Arthur. 1976. Crimes contra a Segurança Nacional: comentários, legislação, jurisprudência. São Paulo: Revista dos Tribunais.

D'Araujo, Maria Celina e Castro, Celso. (orgs). 1998. Ernesto Geisel. $5^{\text {a }}$ Ed., Rio de Janeiro: FGV.

Dreifuss, René Armand. 1981. 1964: A conquista do Estado. Petrópolis: Vozes.

Kinzo, Maria D’Alva. 1988. Oposição e Autoritarismo - Gênese e Trajetória do MDB (1966-1979). São Paulo: Ed. Vértice/R.T.

Klein, Lucia e Figueiredo, Marcus. 1978. Legitimidade e Coação no Brasil pós-64. Rio de Janeiro: Ed. Forense Universitária.

O’Donnell, Guillermo. 1986. Contrapontos: autoritarismo e democratização. São Paulo: Ed. Vértice.

O'Donnell, Guillermo. 1987. B.A: Reflexão sobre os estados burocráticos-autoritários. São Paulo: Ed. Vértice/R.T.

Quirino, Célia Galvão e Montes, Maria Lúcia. 1987. Constituições Brasileiras e Cidadania. São Paulo: Ed. Ática.

Tavares, Aurélio Lyra. 1977. O Brasil de minha geração. $2^{\circ}$ Volume. Rio de Janeiro: Biblioteca do Exército.

Vieira, José Ribas. 1988. O Autoritarismo e a Ordem Constitucional no Brasil. Rio de Janeiro: Ed. Renovar. 